\title{
Islamic architecture: between moulding and flexibility
}

\author{
M. F. Mahmoud ${ }^{1,2} \&$ M. I. Elbelkasy ${ }^{3}$ \\ ${ }^{1}$ Department of Architecture, Cairo University, Egypt \\ ${ }^{2}$ Effat University, KSA \\ ${ }^{3}$ Department of Architecture, Umm Al-Qura University, KSA
}

\begin{abstract}
Islamic architecture reflects the cultural variations of Islamic societies and expresses the cultural movements of these societies. At the same time, it preserves the identity by taking into account the social and environmental properties and artistic constituents. Contemporary global variables (globalization) increase Islamic countries' challenges to keep the Islamic architecture identity which is confined to (tradition and originality), (contemporary and modernism) or forms which were produced in the past and didn't express the meaning of it. The research will discuss the dilemma between form and meaning in Islamic architecture, and it will try to answer an important question: could architectural thinking emerge from Islam (come from Islamic sharia) or not? Answering this question will make a real flexible Islamic architecture consider the identity, social and cultural properties of a variable community. The main aim of the research is to analyse harmony between the Islamic architectural elements and sharia and how can we apply it to our modern architecture to show the flexibility of these elements, which are not dependent on one mould. The study is based on a theoretical and applied analytical approach where the theoretical study deals with the theory of Islamic architecture, Islamic architectural elements, the signification of Islamic architecture and the dilemma between physical and spirit. The applied analytical approach analyses modern architecture projects using Islamic architectural elements to show the flexibility of these elements and finally results, recommendations, and conclusion

Keywords: Islamic architecture, moulding, flexibility, architectural elements.
\end{abstract}




\section{Introduction}

Islam arises in a humble urban environment hence there wasn't any important building in Makkah except "Ka'pa", but when the prophet Mohamed (PBUH) immigrated from Makkah to Madinah he established an Islamic society where some urban and architectural features appeared when he $(P B U H)$ built his first Masjid. Islamic religion spread in a wide area and dealt with other civilizations which produced a distinguished architecture in all Muslim countries, the factors that transmuted and welded a host of varying modes of building into one style possessing individual characteristics was the faith of Islam and took into account the social and environmental properties and artistic constituents of these varying cultures. Islamic thought depends on the constituent's signification and variation in forms which related to environment and culture, this principal produce various Islamic styles around the Islamic worlds like "Mamluk and Fatimid" styles in Egypt, "Moroccan" style in Morocco and Al-Andalus (Spain) [1], all of these styles have the same reference which is Islamic shareãa; this research tries to find the principles which formed the basics of Islamic architecture and how can we use the architectural elements related to Islamic shareãa in new architecture.

\section{Cultural components of Islamic civilization}

Islamic civilization is characterized by three main cultural components which gave its distinctive character among ancient and contemporary cultures, the first is composed of the Qurãan, Sunnah and the Islamic creed which represent the main sources of legislation in Islamic jurisprudence and the unification of the Creator and faith supernatural in a unique composition associates physical and spiritual, while the second is the humanitarian approach of the Islamic culture where it's not linked to certain nation or place but contain all peoples and cultures that did not oppose the Islamic faith, while the third component is the distinctive balance between the physical and the spiritual sides [2].

\section{Islamic architectural thought}

Architectural thought is defined as the outcome of the interaction between all the human spiritual, intellectual and environmental aspects under available technology that complement the process of interaction. Hence, the architectural thought doesn't differ in its components, but differs in the meaning, where the effect of the creed aspects affects the human thought and spirit, which becomes one of the main components of the process of thinking and creativity which represents the starting point and reference for any intellectual and creative product. Therefore Islamic architectural thought can be defined as the outcome of the interaction between the religious beliefs, customs and traditions as a selfreference with the surrounding environmental factors. This makes consistency in the meaning of architectural product in spite of the change in the final form of the product as a result of the influence of different environments [3]. 


\section{Moderation and Islamic thought}

Islam a religion of moderation as it encourages Muslims to take an intermediate and balanced position between the deferent extremes and do not tend to any party rather than other parties, not excessive or negligence nor hyperbole or contract but it is moderation and fairness between the physical and spiritual, realism and idealism, individual and collective. It is said in the Qurãn:

(And I've made you a middle nation to be witnesses over mankind and the Messenger will witness you) (Al-Baqarah verse 143) [4].

Moderation is the basis of Islamic thought, it is the denominator and the basic origin of the Islamic faith, its most important feature is to keep pace with human nature as created by God and acknowledge the existence of human tendencies, therefore Islamic thought was able to balance between what is physical and what is moral (spiritual), The meaning of moderation rather than the arithmetic mean of the area between the two parties but is a point bears the characteristics of each of the parties with all the consistency and fit to form a third attitude represents moderation [5], and then reflected on all life fields and thus the architectural thought, which deal with the human as a combination of body and soul (spirit), which distinguishes Islamic architecture throughout the ages (fig. 1).

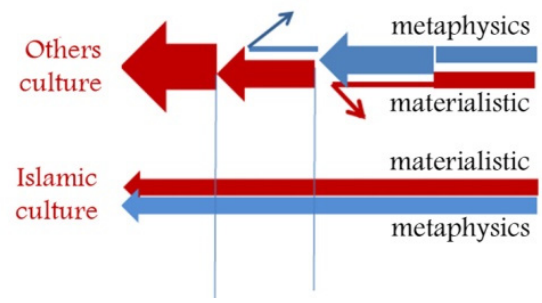

Figure 1: Representation of the main components of a human being.

\subsection{Moderation and Islamic architecture}

As defined earlier, moderation in Islam could be seen as a point that bears the characteristics of different sides to form an inimitable intermediate and moderate position, in the same way the moderation in architectural thought deals with the relationship between both components of architectural work (form and meaning). Form is the physical image perceived by Man, while meaning is the spiritual extension of architecture, which achieves the psychological satisfaction of Man toward the architectural product. The relationship between form and meaning in architecture can be classified into three attitudes as follows:

\subsubsection{The tyranny of form over meaning (functionalism)}

It took an extreme thought in the beginning by trying to represent the machine performance on architecture through form composition as a result of the physical function, which represents a condition lacking spirit and life considering the building like a machine, which achieves the physical dimension of architecture without considering the spiritual and psychological needs of the user. 


\subsubsection{Form and function}

A condition that means achieving balance and harmony between form and function, which presented in the organic architecture by Frank Lloyd Wright, where the form represents the expected outcome of the integration between function and environment and is not imposed by external factors and the functional data only.

\subsubsection{Islamic architecture (moderation)}

Islamic architecture was emerged from Islamic thought, which could be described as an approach combining material, thought and spirit points, which creates the need for functional development of the architectural spaces which adds life and flexibility to the architectural work. Islamic architecture reflects the human dimension in buildings on the level of form and meaning which is representing a combination between physical and symbolic. The meaning in Islamic architecture denotes a comprehensive expression including not only functionality but it combines all the physical, functional components and even faith requirements, it goes beyond the plastic vacuum to achieve perceptible physical requirements of the space to what is more superior than physical by applying motifs as an example that represents a key element in the Islamic architectural composition [6].

\section{The role of meaning in contemporary language of Islamic architecture}

Meaning in Islamic architecture expresses a set of rules and principles that created this architecture, Whereas the architectural vocabulary of the exterior and interior forms were complementary to this foundation so that the architectural product combines between fixed (religious beliefs) and variable (the form), which gives a distinctive character for the Islamic architecture despite different locations. For example, the privacy is one of the most important principles which are based on the principle of "Don't cause harm or return harm" which is basically a doctrine principle was treated by the Muslim architect through the inward orientation of the building and minimizing, directed as much as possible, the external openings or by covering external openings with different treatments like "Mashrabiya" and "Roshan" as well as the use of bent entrances. And can notice easily the use of different methods of dealing with the architectural vocabulary from one place to another but, in essence, represented different solutions to express and deal with the Islamic meaning of privacy. From the previous presentation, we can find that the meaning in Islam was the link between Islamic architecture over the centuries, which must be followed in the process of searching for roots of the contemporary architecture, this process which was treated throughout many different trends which can be summarized in three directions are as follows [3]:

- A superficial attitude tends to overcome the heritage by merging architectural heritage vocabulary with the elements of modern architecture. 
- An attitude uses traditional elements without deep understanding.

- A conscious attitude uses heritage with full awareness of the meaning of vocabulary and heritage assets reproduction without falling into the trap of copying and simulation.

In addition, it has emerged another vision adopted a trend thought towards total contemporary and the owners of this trend call for globalization and search for the absolute modernity under the pretext that what was appropriate for the past is not necessary fits for the present and future, which led to create architectural works far from the culture, spirit and identity of the places where it was built.

\section{Main principles of Islamic architecture}

Any architectural thought is built on a set of principles that distinguish it from other architectural trends. Islamic architectural thought has been established on a set of principles that took into account the values determined by Islamic law "Shareãa". Current research raises a vision based on that the Islamic architecture depends on emphasizing the meaning power instead of the fixed moulds. This meaning is associated to one or more of the established principles stemming from the concepts of creed, dealing with this meaning provide flexibility to deal with diverse and flexible applications, where the compatibility of these applications with the original principle makes them called "Islamic" not the concept of those fixed forms. The diverse and renewable architectural treatments offer greater flexibility and innovation to allow different applications to meet the requirements of the meaning and basic principle.

To illustrate this vision we can review two of the most important principles of the Islamic vision for the urbanization of Earth, shows the principle and the concept of "succession" as a fundamental base for Islamic thought stems from the idea that God created man and made him a successor in the ground and this means that he is asked to benefit from all resources within the context of responsibility to work to preserve, protect and develop them for next generations. We can also highlight the principle of "Don't cause harm or return harm" as one of the most important principles of Islamic thought, which formed the vision of Islamic architecture and urbanism, which is a principle combines achieving functional benefits and social responsibility in a strong bond ensures the attainment of individual's interest in a line with the community's interest in a balanced manner. Among the most important applications that the current research traces as they may have been associated with these two principles, we can find the inward orientation, building outer protection, privacy, environmental design and sustainability. While a wider range of diverse architectural treatments could be highlighted trying to translate these applications to meet the previous main principles such as: "inner courtyard", "Mashrabiya", and "double and isolated walls" with a variety of different and innovative solutions. 


\section{Analytical study of contemporary examples}

The analytical part of the study aims to view a set of architectural treatments used in contemporary projects, which are associated with the previously mentioned principles of Islamic architecture, then trying to trace the relation between those treatments, applications and conceptual principles to check the validity of the study hypothesis.

\subsection{Study sample}

The study sample was selected to include a set of projects among the last century which present different architectural styles reflecting pre-elucidated approaches and showing a wide range variation of used treatments. The list included residential, commercial, and cultural buildings. It comprised around 40 buildings but according to limitations of the current study, only 6 examples will be presented to illustrate the methodology and outputs of the analytical study.

\subsection{Analysis methodology}

The study of the selected projects was applied according to three main phases. In the first phase, an introductory brief of the projects was introduced. In the second phase, the researchers studied the link between the used treatments and the stated applications and the results of this phase were presented in a form of comparative matrix. The third phase attempts to link the output of the previous two phases to build a good understanding of the mechanism of this relation.

\subsection{Phase I: projects brief}

\subsubsection{Zaghlol apartments building, Cairo}

Zaghlol apartments is a residential building built in 1986, Cairo. It contains five floors and a basement, the building entrance is located in the basement floor, ground and first floors are residential villa while the typical floors are apartments. The architect used the courtyard for privacy; increase day light and the movement of nature air by opening the court yard in the ground floor which helps the architect to decrease windows in the southern elevation.

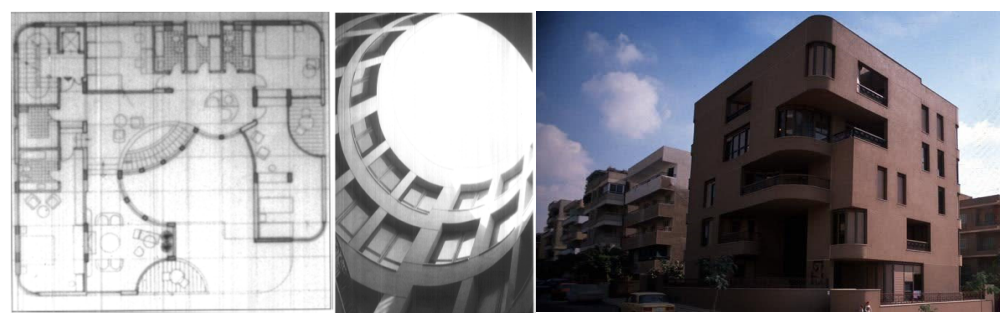

Figure 2: Zhaglol apartments, Cairo. 


\subsubsection{National Commercial Bank, Jeddah}

National commercial bank project is an administration building located in Jeddah - KSA, the design concept is making courtyard to make inward orientation and protect the building envelop by solid walls to control high temperatures and moisture, the designers made halls in the outer walls to move air in the courtyard and providing shadow to the glass walls looking to the courtyard.

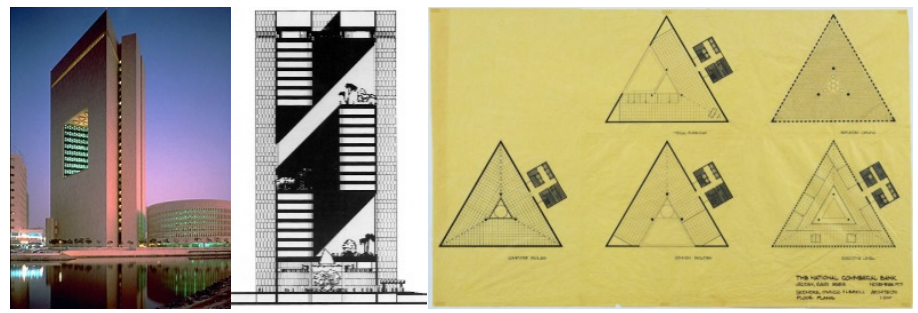

Figure 3: National Commercial Bank, Jeddah.

\subsubsection{Gourna Project, Upper Egypt}

Gourna is a project to relocate the village of Gourna near the valleys of the kings, queens in Luxor; Hassan Fathy designed the village as a prototype that might provide an answer to the problem of housing in the Egyptian villages. Fathy divided the village lay out to four quarters separating by broad streets which meeting in the square to connect public buildings, to ensure good ventilation and isolation of the blocks of houses. The houses had various designs to suit the people who would live in it, a lot of treatments appeared in Gourna design like bent entrance, wind catchers, courtyard and using local building material [7].

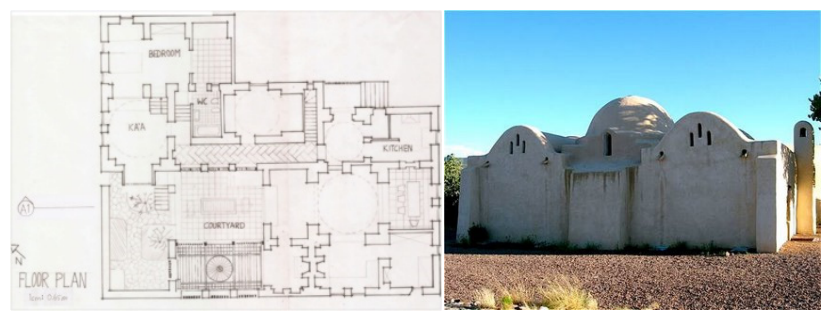

Figure 4: Gourna Project: plans and exterior images.

\subsubsection{Halawa House, Alexandria}

"Halawa" house designed by architect Abd-Alwahed Alwakel in 1972 in AlAgamy - Alexandria and the house won the Aga-khan prize in 1980, it designed around the courtyard as a center of all activates and to provide privacy, the house contains two floors the ground one has entrance, living room, visitors bed room and courtyard which included Al-Majlis. The first floor including two bed rooms and the master bed room with a terrace, the designer used several traditional treatments like wind catchers, courtyard, bent entrance and "Iwan" [8]. 


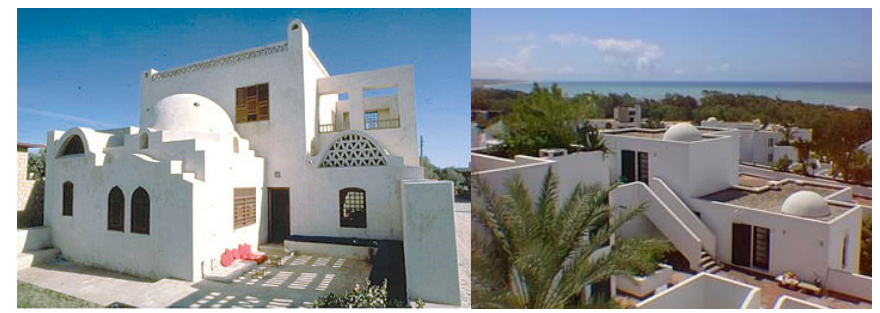

Figure 5: Halawa House, Alexandria.

\subsubsection{Justice Palace, Riyadh}

The project of "Qasr al-Hukm" is located in mid-town of Riyadh the capital of Saudi Arabia the project designed by architect Rasem Badran, the project is a complex contains the mosque, the palace of justice and commercial area. Badran used natural light and into the prayer hall and used the columns as conduits for the mechanical ventilation system. The palace recalls the morphology of the old city of Riyadh through the use of walls, gates and towers. Badran connected the project elements by plazas first one is larger than the second one between the mosque and the palace which acts as intermediary space both plazas are formally landscaped and the arcade that holds the bridge connecting the palace and the mosque and acts as a gateway [9].

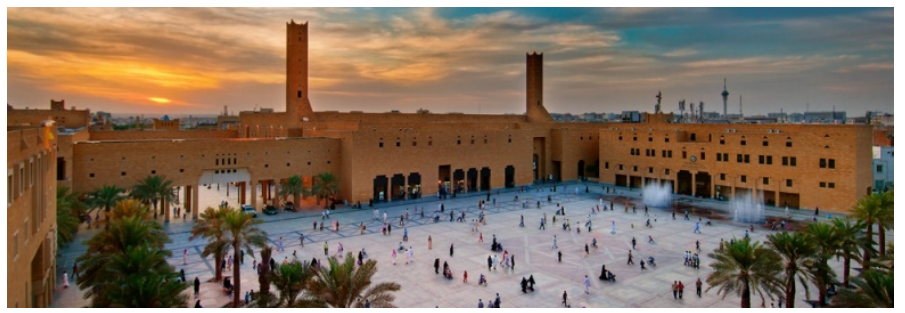

Figure 6: Justice Palace, Riyadh.

\subsubsection{Arab World Institute, Paris}

The project of Arab world institute in Paris is one of the most important projects in the last century it won Aga khan prize in 1989. The project importance is related to being the connection between Arab world culture and European culture; the designers used some traditional treatments like court yard and they used mechanical parts to control the light percentage in the southern elevation like (Mashrabia). The project is compatible with its environment so the architects use the modern style which appears in glass envelop and used traditional element with a modern treatment to protect the southern façade [8]. 


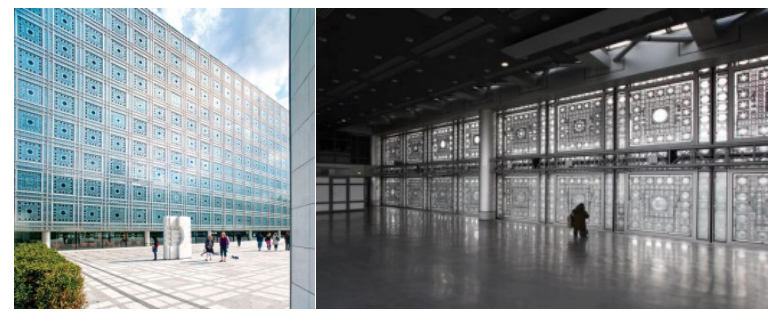

Figure 7: Arab World Institute, Paris.

\subsection{Phase II: comparative matrix}

Table 1 represents a proposed tool to monitor the interrelation between the used treatments and their impact on the desired applications in association with the theoretical principles; the horizontal Rows represent the treatments used in each project while the vertical columns represent the applications and principles.

\subsection{Phase III: analytical conclusion}

The observation and analysis of the comparative matrix outputs shows a great flexibility of the used architectural treatments expressing different applications to achieve the constant theoretical principles. In order to explain that we can take one treatments as an example; The courtyard is considered as one of the most important traditional architectural elements that achieve the application of inward orientation, it provides natural lighting and ventilation for the building and interior spaces without the need to have large openings in the exterior of the building, which also helps in achieving the principle of privacy, which works successfully with the principle of "Don't cause harm or return harm". It also complies with the warm humid environment and dry (some other accessories could be added processors to control the humidity), which works with the concept of "succession". Recently the courtyard was disappeared or rarely used due to the nature of high density residential projects, by applying multi-floors solutions with different users, which resulted a massive reduction of privacy as the dimensions of pieces of land and rising prices helped the disappearance of

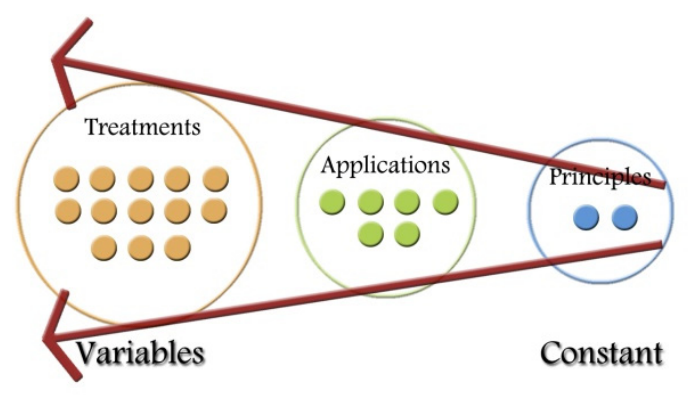

Figure 8: Representation of interrelation between principles and treatments. 
Table 1: $\quad$ Comparative matrix.

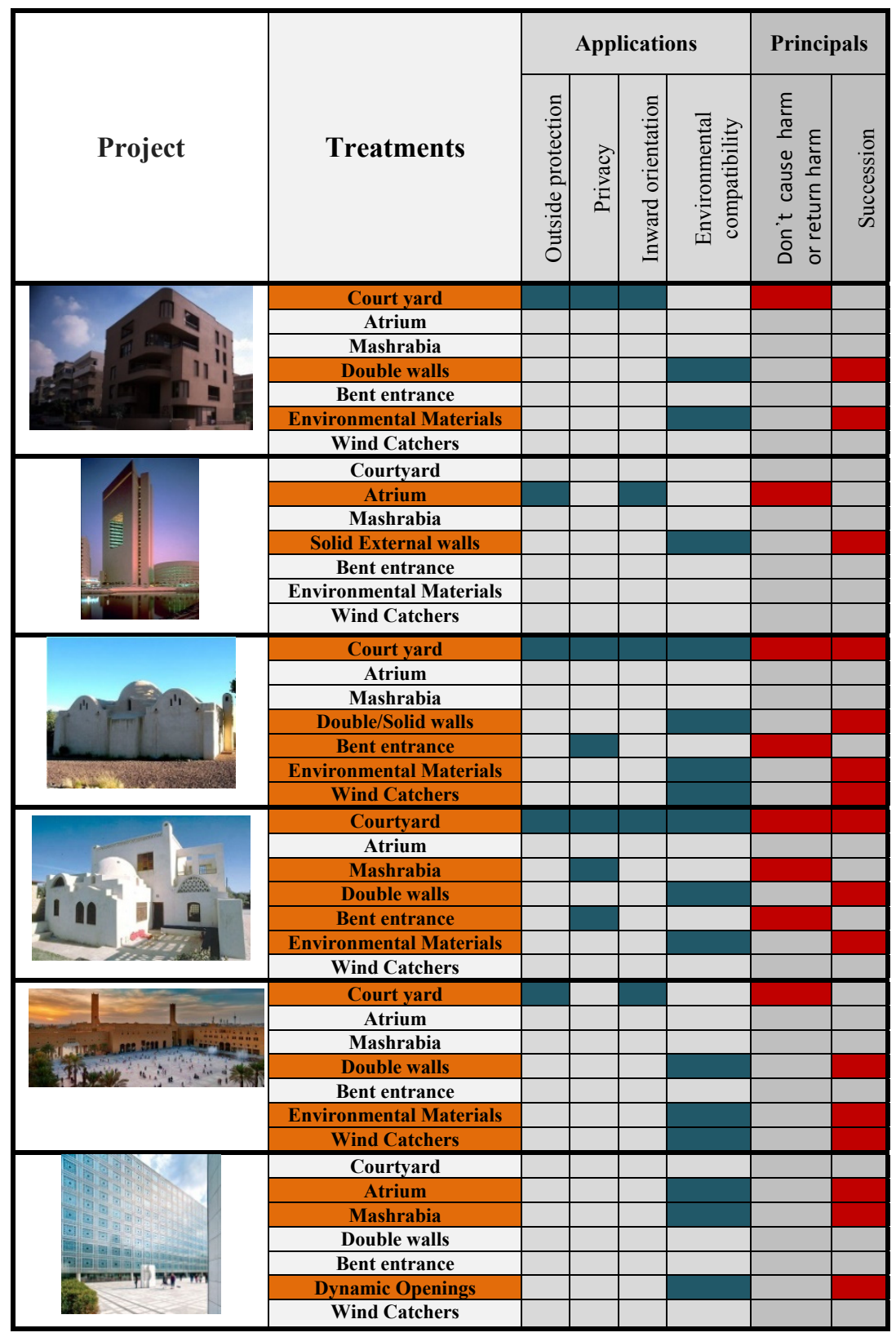


the courtyard. In this case, we notice that the "Atrium" treatment could introduce an alternate solution to express those applications or by adding some modifications to the traditional courtyard model as noticed by the analysis of the studied projects.

\section{Remarks and conclusion}

Through the exploration of this study, we can introduce a new understanding for Islamic architecture as a flexible concept, not a fixed mould. This relies on two main ideas:

- Understanding the design process depends on the value of the human mind in Islam which gives an unlimited freedom to innovate and develop. This comes through defining a set of constant principles and releases the use of tools and techniques.

- The human approach of Islamic architecture focuses on the two main components of man (body and soul) as one entity which appeared in the previous principles.

The current study introduces a preliminary consideration which constructs for a new approach of a reference work for main Islamic principles and their applications in architecture.

\section{Acknowledgement}

The authors would like to thank Deanship of Scientific Research at Umm AlQura University (Project\# 43408003) for the financial support.

\section{References}

[1] Petersen, A., Dictionary of Islamic Architecture, Taylor \& Francis e-library, 2002.

[2] https://www.uop.edu.jo/download/research/members/3khassaesseSpecificitesar.pdf

[3] Habib, T., Alqadi, Sh., Conceptual framework for using Islamic architectural heritage in contemporary Arabic cities, published research, Urban Heritage in Arabic cities between Preservation and Authentication Symposium, Hems, Syria, 2001.

[4] Holy Qurãan.

[5] Umara, M., Islamic Methodology Features. Methodology series (3), $1^{\text {st }}$ edition, International Institute for Islamic Thought, Virginia, USA, 1991.

[6] Yassen, A., Religious Symbolism in Islamic Ornament, Study in Islamic art metaphysics, $1^{\text {st }}$ edition, Zahra Al-Sharq Pub., Cairo, Egypt, 2006.

[7] Steele, J., An architecture for people the complete works of Hassan Fathy, Thames and Hudson ltd. London, 1997.

[8] Serag Al-din, I., Renewal and authentication in Islamic societies' architecture, Bibliotheca Alexandrina, Egypt, 2007.

[9] Steele, J., The architecture of Rasem Badran narratives on people and place, Thames and Hudson Ltd. London, 2005. 